\title{
MECHANICAL AND TRIBOLOGICAL BEHAVIOUR OF AL 7075 HYBRID MNC'S USING STIR CASTING METHOD
}

\author{
N SREEDHAR $^{1} \&$ S BALAGURU ${ }^{2}$ \\ ${ }^{1}$ Research Scholar, Department of Mechanical Engineering, Vel Tech Rangarajan \\ Dr. Sagunthala $R \&$ D Institute of Science and Technology, Chennai, India \\ ${ }^{2}$ Professor, Department of Mechanical Engineering, Vel Tech Rangarajan \\ Dr. Sagunthala $R \& D$ Institute of Science and Technology, Chennai, India
}

\begin{abstract}
Nanocomposites in the metal matrix due to their high strength, good corrosion resistance and good resistance to wear, play a significant function in various engineering sectors of aerospace, automotive, defense, and marine. In this investigation, efforts have been provided to increase the wear and mechanical characteristics of HAMCs. Al 7075 was selected as matrix and silicon carbide (50nm), aluminium oxide (30nm) particles (0\%, $2.0 \%, 4.0 \%$, 6.0\%, and 8.0wt. \%). Magnesium has been incorporated (1.0\%) to improve the wettability of $\mathrm{SiC}$ and $\mathrm{Al}_{2} \mathrm{O}_{3}$ nanoparticles in the aluminum alloy. The nanocomposites are made using the liquid state (stir casting) process. The analysis of optical microscopy revealed the microstructure of the hybrid nanocomposites $\mathrm{Al7075}_{2} \mathrm{Al}_{2} \mathrm{O}_{3} / \mathrm{SiC}$. Nanoparticles, such as silicon carbide and aluminum oxide were evenly distributed in the Al matrix that could be examined using an SEM (scanning electron microscope). The results show that by adding nano reinforcement particulates in the molten matrix, wear and mechanicalcharceteristics increase compared to base alloy Al 7075.
\end{abstract}

KEYWORDS: Aluminium 7075, $\mathrm{SiC}, \mathrm{Al}_{2} \mathrm{O}_{3}$, Optical Microscope \& Scanning Electron Microscope

Received: Apr 02, 2020; Accepted: Apr 22, 2020; Published: May 06, 2020; Paper Id.: IJMPERDJUN202036

\section{INTRODUCTION}

Aluminum composites are mainly employed in automobiles, sports goods, aircraft, marine, construction applications due to greater strength, high machinability, good wear and corrosion resistance [1]. Al7075/nano-SiC showed improved durability as well as strength over the alloys, but impaired crack strength and ductility. In recent developments, metal matrix composites have come together to meet the growing overall demand for lightweight, high-performance, eco-friendly, wear-resistant, and corrosion resistant materials. Hybrid metal matrix composites (HMMCs) are used extensively in advance due to its enhanced mechanical properties and lighter density compared to metals/alloys, particularly in applications where weight and strength are of the greatest consequence [2]. The advantages of particle reinforced compounds over others are their cost-effective formability and their different reinforcement mechanisms. Hybrid metal matrix composites (HMMCs) are ideal for applications that require properties such as combined resistance, thermal conductivity damping characteristics, thermal expansion coefficient, and less mass [3]. The special features of HAMMCs improve their use in automotive and tribological applications, such as brake disks, cylindrical blocks, pistons, and brake drums. The composites of Silicon carbide reinforced aluminum matrix are considered to be vital for aerospace and electronic applications, and are therefore very much based on these composites. Aluminum oxide $\left(\mathrm{Al}_{2} \mathrm{O}_{3}\right)$ has better reinforcing properties and it would be encouraging for $\mathrm{SiC}$ to reinforce it. However, only limited work on the two reinforcement particulates has been 
found in the literary works $[4,5]$.

The primary objective is to produce a cost-effective, lightweight nanocomposite. In the current investigationAl 7075, $\mathrm{Al}_{2} \mathrm{O}_{3}(30 \mathrm{~nm})$, and $\mathrm{SiC}(50 \mathrm{~nm})$ was chosen as matrix and reinforcement particles. $\mathrm{Al} 7075 \mathrm{MMNCs}$ were made using a stir casting method and studied the wear and mechanical properties. Also, the homogeneous distribution of nanoparticulates is examined by analyzing microstructures for various nano $\left(\mathrm{Al}_{2} \mathrm{O}_{3}+\mathrm{SiC}\right)$ composite weight percentages.

\section{MATERIALS AND COMPOSITIONS}

\subsection{Material Selection}

Al 7075 was chosen as base material and, silicon carbide, aluminum oxide particles with an average particle size of (30, 50 $\mathrm{nm}$ ) have been utilized as nano reinforcement materials [6]. Tables 1 and 2 show the chemical composition of aluminum 7075 and the thermal properties of nano reinforcement particles.

Table 1: Composition of Al7075 HMMCs

\begin{tabular}{|c|c|c|c|c|c|c|c|c|c|c|}
\hline Al 7075 & Cr & Fe & Ti & Mn & Zn & Mg & Si & Cu & others & Al \\
\hline Wt.\% & 0.22 & 0.21 & 0.046 & 0.05 & 5.65 & 2.3 & 0.056 & 1.42 & 0.028 & Bal \\
\hline
\end{tabular}

Table 2: Thermal Parameters of $\mathrm{Al}_{2} \mathrm{O}_{3}$ and $\mathrm{SiC}$ Particles

\begin{tabular}{|c|c|c|c|c|c|}
\hline Reinforcement & $\begin{array}{c}\text { Melting } \\
\text { Temperature }\end{array}$ & $\begin{array}{c}\text { Thermal } \\
\text { Conductivity }\end{array}$ & $\begin{array}{c}\text { Themal } \\
\text { Expansition }\left(\mathbf{1 0}^{-6}\right)\end{array}$ & $\begin{array}{c}\text { Young's } \\
\text { modulus }\end{array}$ & Density \\
\hline $\mathrm{Al}_{2} \mathrm{O}_{3}(30 \mathrm{~nm})$ & $2069^{\circ} \mathrm{C}$ & $38.37 \mathrm{~W} / \mathrm{m} \mathrm{K}$ & $10.6 \mathrm{~K}$ & $406 \mathrm{GPa}$ & $3.34 \mathrm{~g} / \mathrm{cc}$ \\
\hline $\mathrm{SiC}(50 \mathrm{~nm})$ & $1675^{\circ} \mathrm{C}$ & $20.65 \mathrm{~W} / \mathrm{m} \mathrm{K}$ & $10.8 \mathrm{~K}$ & $137.98 \mathrm{GPa}$ & $4.10 \mathrm{~g} / \mathrm{cc}$ \\
\hline
\end{tabular}

\subsection{Experimental Setup}

Figure 1 shows the experimental arrangement for the fabrication of nanocomposites. The setup includes stir casting equipment, melting furnace, pre-heated furnace, and stainless stirrer. The stainless steel stirrer is aluminum-coated to withstand high temperatures. Tables 3 and 4 show the stir casting specifications and process parameters.

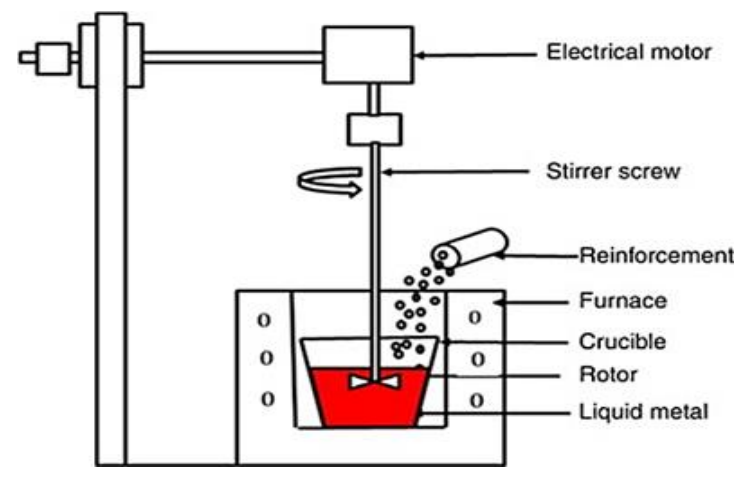

Figure 1: Srircasting.

Table 3: Stir Casting Specifications

\begin{tabular}{|c|c|c|}
\hline $\begin{array}{c}\text { Load } \\
\text { capacity }\end{array}$ & Voltage(V) & $\begin{array}{c}\text { Temperature } \\
\left(\mathbf{0}_{\mathbf{C}}\right)\end{array}$ \\
\hline $3 \mathrm{Kg}$ & $\begin{array}{c}3 \emptyset, \\
450 \text { Volts }\end{array}$ & $100-1500^{\circ} \mathrm{C}$ \\
\hline
\end{tabular}


Table 4: Stir Casting Process Parameters

\begin{tabular}{|c|c|c|c|}
\hline $\begin{array}{c}\text { Stirring } \\
\text { Temperature }\left({ }^{\mathbf{0}} \mathrm{C}\right)\end{array}$ & $\begin{array}{c}\text { Preheat } \\
\text { Temperature }\left({ }^{\mathbf{0}} \mathrm{C}\right)\end{array}$ & $\begin{array}{c}\text { Stirring } \\
\text { Speed (rpm) }\end{array}$ & $\begin{array}{c}\text { Stirring } \\
\text { Time }\end{array}$ \\
\hline $\mathbf{7 5 0}$ & 650 & 680 & $5 \mathrm{~min}$ \\
\hline
\end{tabular}

\subsection{Experimental Work}

The stir casting technique is made use of for the manufacture of hybrid composite materials, in which, the distributed phase is combined with the molten matrix metal using a mechanical mixing process. In this research study, $\mathrm{Al} 7075 / \mathrm{SiC} \mathrm{Al}{ }_{2} \mathrm{O}_{3}$ metal matrix was prepared by the stir casting method. Figure 1 reveals the stir casting equipment used. In this investigation, 1000 grams of 7075 lightweight aluminum alloy as well as the required amount of $\mathrm{Al}_{2} \mathrm{O}_{3}$ and also $\mathrm{SiC}$ powder was chosen for the manufacture of $\mathrm{Al} 7075 \mathrm{MMCs}$. The nano fragments $\mathrm{Al}_{2} \mathrm{O}_{3}, \mathrm{SiC}$ as well as their mix have been pre-heated to $650{ }^{\circ} \mathrm{C}$ for $3 \mathrm{hrs}$ to get rid of moisture. Light-weight $\mathrm{Al}$ has been melted into electric oven. However, then the melt was cast right into a clay graphite crucible and also hexachloroethane tablets, which were made use of for degassing [7,8]. Lightweight aluminum metal is melted at a temperature level of $750^{\circ} \mathrm{C}$. The melt is then drop down to a semi-solid state and combined with pre-heated reinforcement fragments. Once more, this slurry is heated to a completely fluid state as well as combined thoroughly. The temperature of the melt was raised to $650^{\circ} \mathrm{C}$ and also stirred with the aid of a stainless steel stirrer. The mixing was kept for 5 mins at a rate of $680 \mathrm{rpm}[9,10]$ To boost the wettability, with all composites, 1.0 percent of pure $\mathrm{Mg}$ has been added. The temperature of the melt was kept at $750^{\circ} \mathrm{C}$ throughout the enhancement of the reinforcement fragments $[8,9]$. The dispersion of the reinforcement fragments was accomplished utilizing the vortex technique. The melt with the reinforced particles was put right into the metal mold. The melt was after that enabled to solidify in the mold and mildew. Hybrid MMC samples were made with different mixes of resources (in percent) as shown in Table 5. To figure out, hardness, tensile strength, $\%$ of elongation as well as wear performance composite specimens wasfabricated, as per ASTM specifications. The microstructures of the nanocomposites were performed by optical microscope and SEM evaluation.

Table 5: Compositions of Samples

\begin{tabular}{|c|c|c|c|c|}
\hline \multirow{2}{*}{$\begin{array}{c}\text { Sample } \\
\text { No }\end{array}$} & \multicolumn{4}{|c|}{ Composition( Wt in \% in grams) } \\
\hline & Al 7075 & $\begin{array}{c}\text { Magnesium } \\
\text { (Mg) }\end{array}$ & Nano- $\mathrm{Al}_{2} \mathrm{O}_{3}$ & Nano-SiC \\
\hline 1 & 1000 & 1 & 0 & 0 \\
\hline 2 & 1000 & 1 & 2 & 2 \\
\hline 3 & 1000 & 1 & 4 & 4 \\
\hline 4 & 1000 & 1 & 6 & 6 \\
\hline 5 & 1000 & 1 & 8 & 8 \\
\hline
\end{tabular}

\section{RESULTS \& DISCUSSIONS}

Aluminum $7075 / \mathrm{SiC} / \mathrm{Al}_{2} \mathrm{O}_{3}$ hybrid composites obtained by the mechanical stirring method and the following test of tensile strength, hardness, \%of elongation, COF, and rate of wear to enable for its wear assets [11].

\subsection{Density}

Density is the crucial features of composites that reveal them. The experimental values are performed utilizing the Archimedes principle [12]. Figure 2 graphically describes analytical (theoretical) and research (experimental) values. Initially, the theoretical density of $\mathrm{Al}$ alloy is very compare to experimental density. 


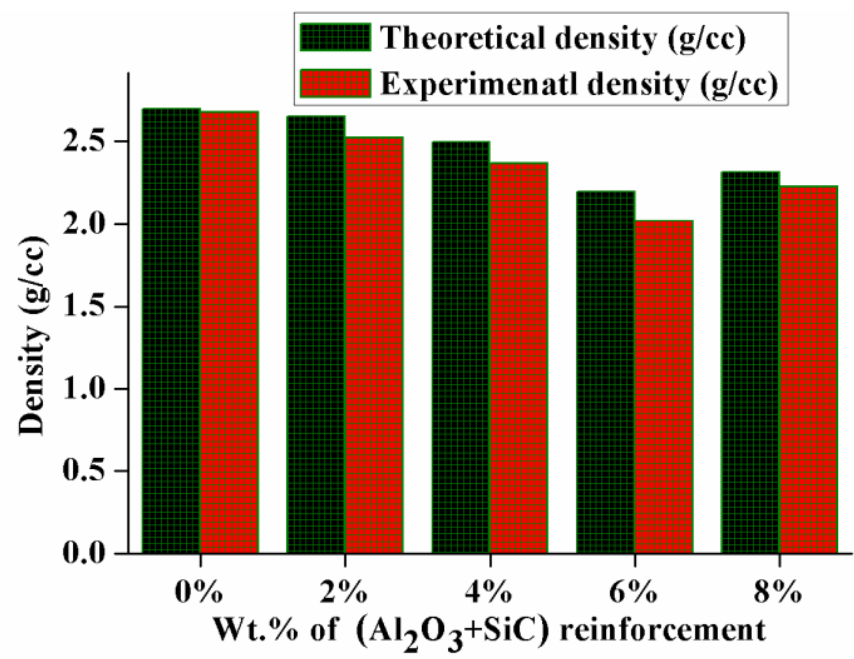

Figure 2: Graphical Representation of Density for alloy and Metal Matrix Nanocomposites.

Figure 2 illustrate, the specimen with a 6 percent concentration of $\mathrm{Al}_{2} \mathrm{O}_{3}$ and $\mathrm{SiC}$ resulted in a very low density of $2.05 \mathrm{~g} / \mathrm{cc}$, while the 8 percent combination of both materials provided a slightly higher density of $2.26 \mathrm{~g} / \mathrm{cc}$. An improved density of approximately $0.52 \mathrm{~g} / \mathrm{cc}$ was achieved when the concentration of reinforcement materials was increased compared to the unreinforced $\mathrm{Al} 7075$ MMNCs.

\subsection{Hardness}

The hardness of 7075 alloy and 7075/( $\left.\mathrm{Al}_{2} \mathrm{O}_{3} / \mathrm{SiC}\right)$ nanocomposites is $95.6 \mathrm{VHN}, 122 \mathrm{VHN}, 140.3 \mathrm{VHN}, 144.6 \mathrm{VHN}$, and $142 \mathrm{VHN}$, respectively. It was found that a greater percentage of nano reinforcement results in higher material hardness. The strength of the $\mathrm{Al}_{2} \mathrm{O}_{3}$ and $\mathrm{SiC}$ particles is improved by preventing the dislocation motion in the $\mathrm{Al}$ matrix and the hard phase nanoreinforcement enhances the resilience of nanocomposite material. Figure 3 indicates that the hardness of the reinforced sample decreased marginally, as the amount of reinforcement decreased. The maximum hardness production of 23.8 percent isidentified in addition of $6 \mathrm{wt}$ \% of composite. However, an additional reinforcement $\left(\mathrm{Al}_{2} \mathrm{O}_{3}, \mathrm{SiC}\right)$ particle decreases microhardness (8 percent).

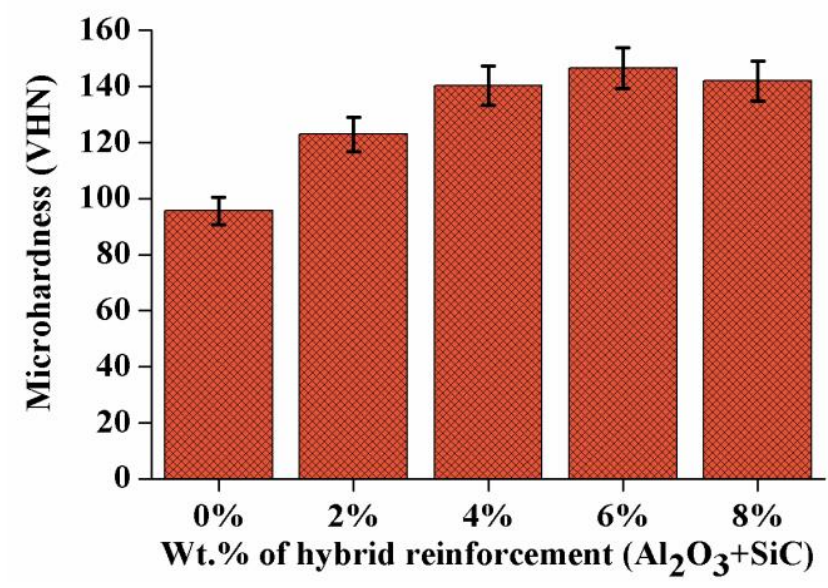

Figure 3: Graphical Representation of Hardness for Alloy and Metal Matrix Nanocomposites. 


\subsection{Tensile Strength}

The tensile test study was carried out in compliance with the ASTM requirements. The test sample size was $10 \mathrm{~mm}$ in diameter and $100 \mathrm{~mm}$ in length. The tests were carried out on computerized UTM. In many applications, the mechanical properties of composites are extremely significant. The results of tensile strength tests are shown in Figure 4, which shows a difference in tensile stamina with an enhancement in $\mathrm{SiC}$ and $\mathrm{Al}_{2} \mathrm{O}_{3}$ particle volume. The experimental results showed that the tensile strength of $\mathrm{Al}$ 7075 was $273 \mathrm{Mpa}$ and the tensile strength of $\mathrm{Al} 7075$ was reinforced with $2 \%, 4$ percent, 6 percent, and 8 percent $\mathrm{Al}_{2} \mathrm{O}_{3} / \mathrm{SiC}$ was $290 \mathrm{Mpa}, 305 \mathrm{Mpa}, 345 \mathrm{Mpa}$, and $325 \mathrm{Mpa}$ when reinforced with hybrid particles. It is because the presence of $\mathrm{Al}_{2} \mathrm{O}_{3}$ and $\mathrm{SiC}$ particles in the aluminum matrix increases resistance to cracking, which results in increased tensile strength[13].

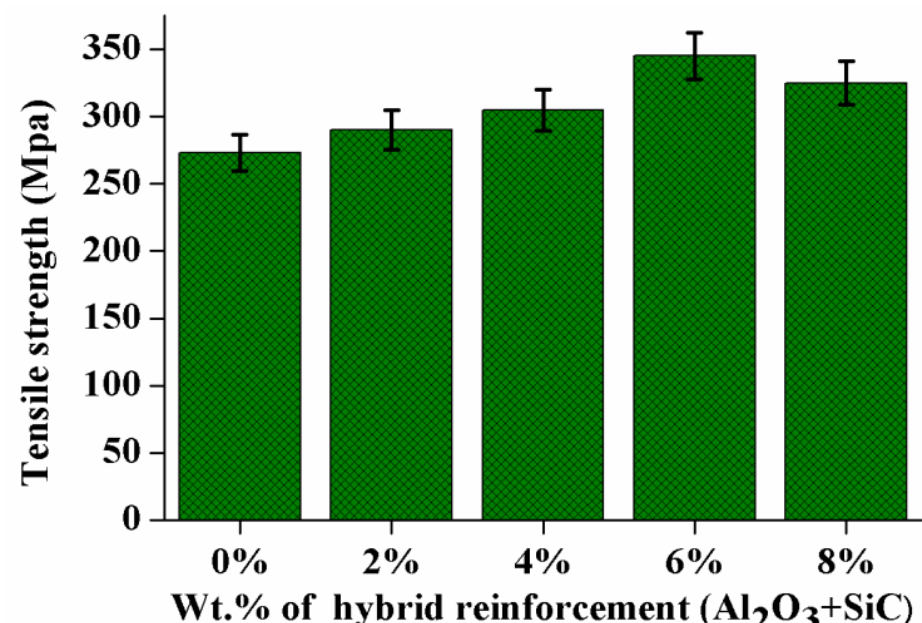

Figure 4: Ultimate Tensile Strength versus. wt..\% of the Nanoreinforcements.

\subsection{Percentage of Elongation}

The percentage elongation of $\mathrm{Al} 7075$ is 4,7\%, and the strength of $\mathrm{Al} 7075$ increased with $2 \%, 4 \%, 6 \%$ and $8 \%$ of $\mathrm{Al}_{2} \mathrm{O}_{3} / \mathrm{SiC}$ is $2,8 \%, 2,3 \%, 1,6 \%$ and 2,0\%, respectively. From Figure 5, it is noticed that the percentage of $\left(\mathrm{Al}_{2} \mathrm{O}_{3}+\mathrm{SiC}\right)$ is increasing enhancing the $\%$ elongation decreases. It can be observed that the percentage elongation of composites is minimal compared to non-reinforced alloys. The significant factor is the direct adsorption relation between matrix and strengthening materials. The low elongation rate is $6 \mathrm{wt} . \%$ (1.6 percent). Additional reinforcement addition (8\%) raises the elongation percentage $[14,15]$

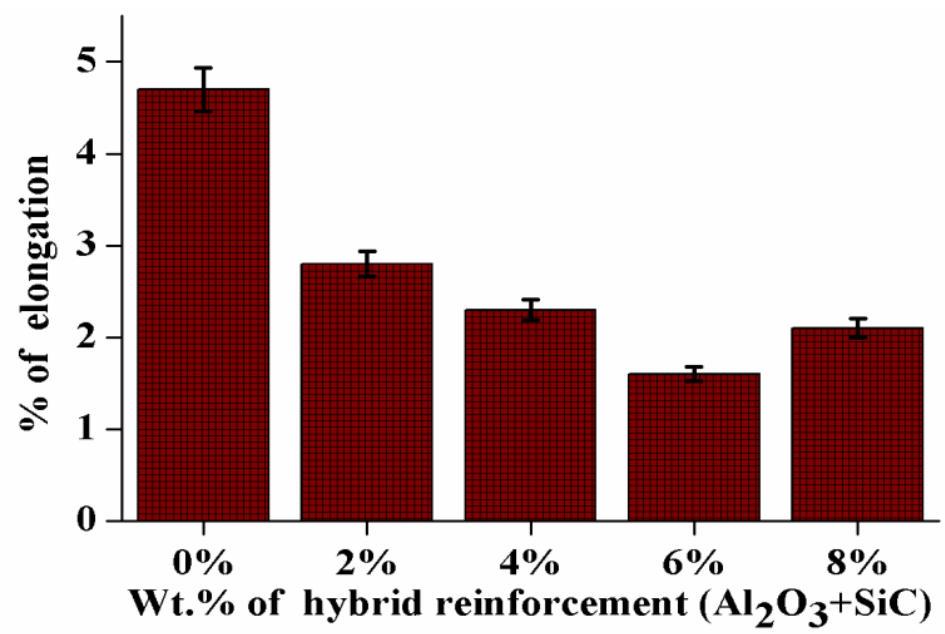

Figure 5: \% Elongation Versus. wt.\% of the Nanoreinforcement Particele. 


\subsection{Wear Behavior}

Dry sliding wear assessments were usually performed using pin-on-disk equipment, as per the standard ASTM G-99. Pin samples of $6 \mathrm{~mm}$ in diameter and $30 \mathrm{~mm}$ in length were machined using a lathe. The pin holder loaded the pins up and down on the EN-31 steel revolving disk[16].

\subsubsection{Effect of Reinforcement Particles on Wear Rate}

The effect of the reinforcement weight percentage on the wear rate is illustrated in Fig. 5(a). The wear rate depends on the strengthening of the composites. The increased reinforcement percentage decreases the wear rate due to the strong interfacial relation between the matrix and the reinforcement. Among the unique enhanced materials, the $6 \mathrm{wt} \% \mathrm{Al}_{2} \mathrm{O}_{3} / \mathrm{SiC}_{\mathrm{C}}$ enhanced composite has a low wear rate, relative to composites of $0,2,4$, and $8 \mathrm{wt} \%$, in all applicable load ranges (10N, 20N, 30N). The wear rate reduction is observed with a weight improvement percent of the hybrid reinforcement due to the hybridreinforcement effect's wear resistance [17]. Higher-weight reinforcement hard particles avoid the incremental wear of the aluminum matrix by reducing the surface deformation due to the load sharing. Due to the large percentage of hard particles on the contact surface, this leads to a lower wear rate relative to other composites, that is, 6 wt. percent of $\mathrm{Al}_{2} \mathrm{O}_{3} / \mathrm{SiC}$ composites.

\subsubsection{Effect of Wear Rate on Applied Load}

Among the other parameters, the applied load is one of the major factorsimpacting wear rate of nanocomposites. It is approximated that the rate of wear of unreinforced alloys is even greater than ofnanocomposites. This is generally due to solid dispersoids that exist on the surface of the nano composites [18]. Hence, increasing the load (10-30 N) results in significant wear rate intensively at $4 \mathrm{~m} / \mathrm{s}$ speed in addition of $6 \%$ nanocomposite as shown in Figure 6(a). Moreover, nancomposite at 6\% exhibits lower wear rate at all sliding conditions and leads to improve wear resistance. From Figure 6(b) shows the arising of 2 to $6 \%$ reinforcement particles may tends to good interfacial bonding in between the reinforcement and matrix as well as the presence of hard $\mathrm{Al}_{2} \mathrm{O}_{3} / \mathrm{SiC}$ particulates.
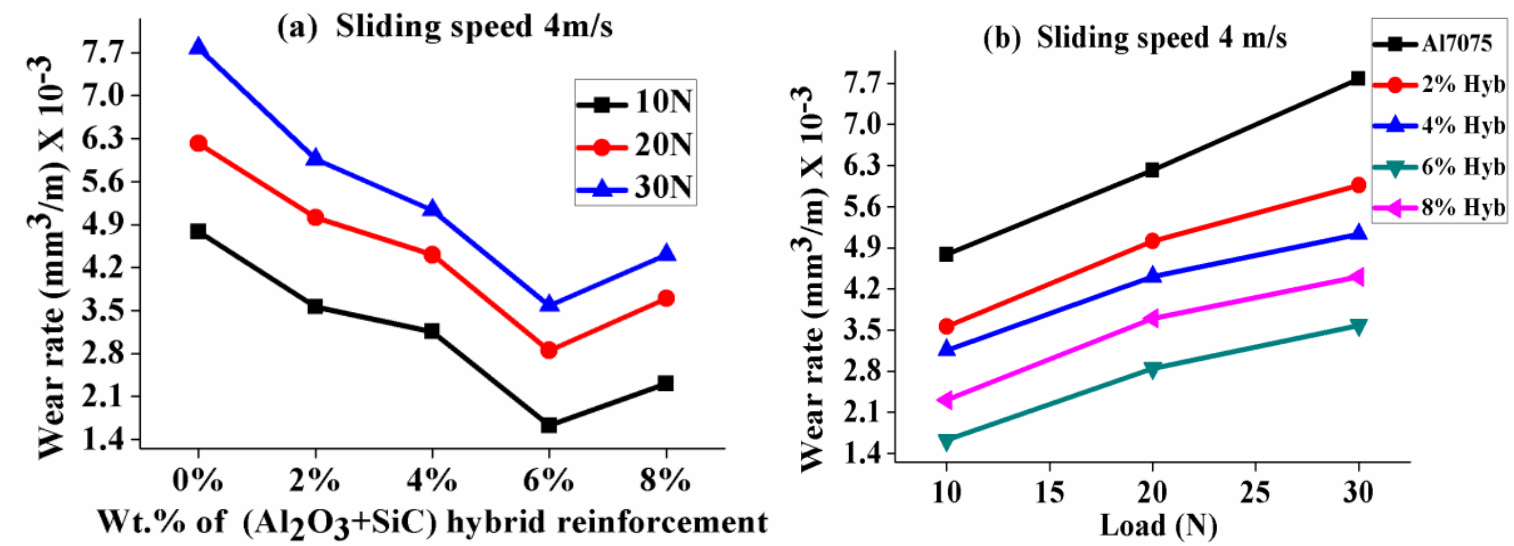

Figure 6: (a) Wear Rate Versus Wt. \% of Reinforcement (b) Load Versus. Wear Rate.

\section{MICROSTRUCTURAL ANALYSIS}

\subsection{Optical Microscopic Analysis}

The composite samples were cut from cast materials and produced by a nanocomposite process specially made.

7(a-e) displays the images of the optical microstructure with 500xmagnification. The samples are polished with Keller agent 
in order to appear material behavior clearly. However, from OM structure, it is that a set pores and some locations without the inclusion of cracks are recognized in base alloy. It is reduced, while addition of hard reinforcement particles increases. Hence, to overcome the cracks and pores a strong homogenous is required and it is diffused through the nano-composite metal matrix [19,20].
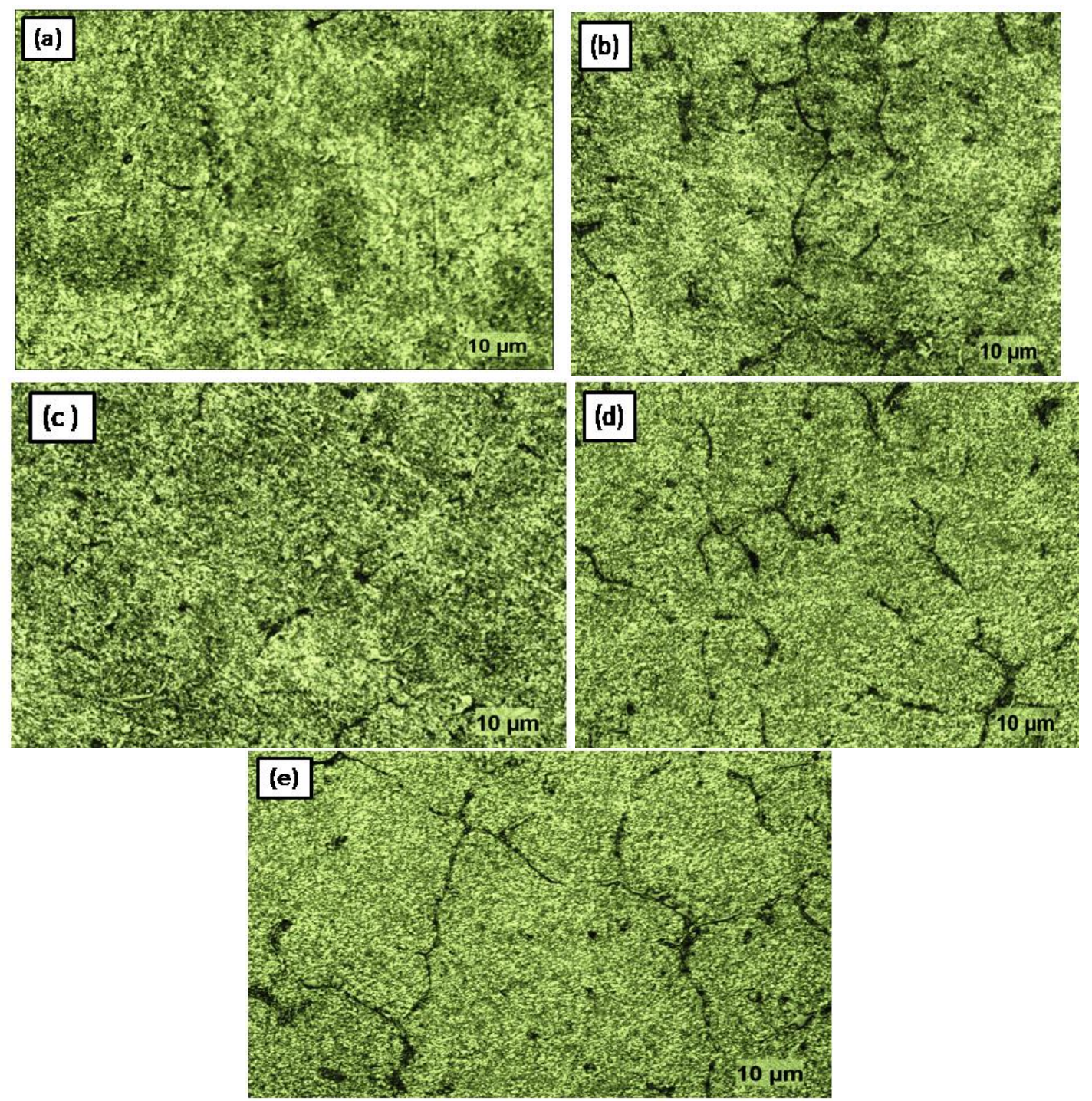

Figure 7: OM Images of (a) 7075 Alloy, (b) 2 wt.\%, (c) 4wt.\%, (d) 6wt.\% and (e) 8wt.\% Nano Composites

\subsection{SEM Analysis}

During the microstructural assessment, nanocomposite specimens were cut off from the casting rods and also grinded through emery paper, and finally polished using warm water for all samples. Fine polishing was achieved by adding a $0.5 \mu \mathrm{m}$ ruby paste in addition to the cellar reagent. The study of specimens in the scanning electron microscope (SEM) identified the dispersion of nano-reinforcement as well as its morphology in the Al 7075/hybrid compounds and its inherent microstructural properties. Figure 8 (a-e) presents SEM surface images of nanocomposites as well as screens that complement the area component of nanocomposites [21, 22]. 

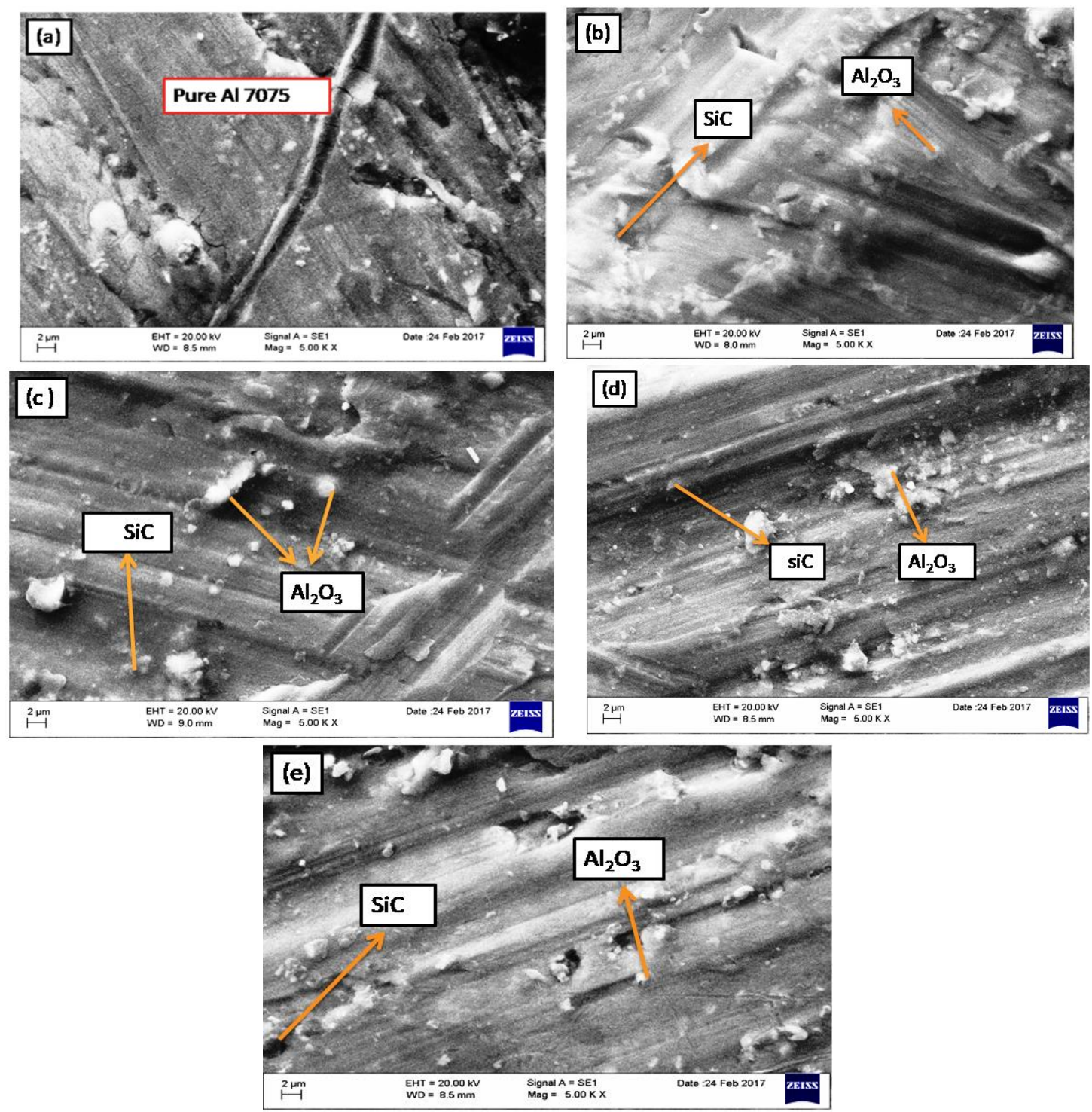

Figure 8: Microstructural Images of (a) 7075 alloy,(b) 2 wt.\%, (c) 4wt.\%, (d) 6wt.\% and (e) 8wt.\% Nano Composites.

\section{CONCLUSIONS}

In the current study, Al7075-based composite is prepared using the stir casting procedure, processing with specific nano$\mathrm{Al}_{2} \mathrm{O}_{3} / \mathrm{SiC}$ weight fractions, and analysis was done with SEM. Mechanical and tribological behaviour was carried out, along with the $\mathrm{Al} 7075$ alloy and the $\mathrm{A} 17075 / \mathrm{Al}_{2} \mathrm{O}_{3} / \mathrm{SiC}$ composite. The following conclusions are summarized as follows:

- The SEM analysisand mechanical properties reveals that, addition of $\mathrm{SiC}$ and $\mathrm{Al}_{2} \mathrm{O}_{3}$ particles possess good uniform distribution between matrixes and reduce the agglomeration.

- The density of AZ91D alloy decreases with an increase in reinforcing content. The lowest density was occurred due to addition of $6 \%$ nano composite.

- The microhardness of aluminium metal matrix nanocomposites was found to be maximum (144.6 VHN) for the weight percentage of $6 \%$. The level of bonding between the matrix material and reinforcement is a significant factor in the improvement of the hardness value of fabricated composite materials. 
- A significant decrease in the percentage of elongation with an increase in the content of particulate reinforcement in the Al 7075 based hybrid metal matrix nanocomposites has been noted. A maximum reduction of $3.2 \%$ in wear rate for composite containing $6 \mathrm{wt}$. $\%\left(\mathrm{Al}_{2} \mathrm{O}_{3}+\mathrm{SiC}\right)$ when compared to the matrix alloy has been observed.

- The highest tensile strength of $345 \mathrm{MPa}$ was obtained for $6 \%(\mathrm{Al} 2 \mathrm{O} 3+\mathrm{SiC})$ hybrid composite. This is because; the addition of high reinforcement nanoparticles acts as a subsequent phase and prevents the movement of dislocation in the matrix composite.

- The wear rate is decreased addition of hard reinforcement particles compare to base alloy and gradually increases due to increasing loads. A maximum reduction of $15.26 \%$ for composite containing $6 \mathrm{wt}$. \% ( $\left.\mathrm{Al}_{2} \mathrm{O}_{3}+\mathrm{SiC}\right)$.

- The minimum wear rate $\left(\mathrm{Al}_{2} \mathrm{O}_{3}+\mathrm{SiC}\right)$ is reached by $6 \mathrm{wt}$. percent. The major factor is the interfacial association between matrix and reinforcement and the hard ceramic particles in the matrix.

\section{REFERENCES}

1. S. Suresh, G. Harinath Gowd, M. L. S. Deva Kumar (2019). "Experimental investigation on mechanical properties of Al 7075/Al2O3/Mg NMMC's by stir casting method”, Sadhana., DOI: 10.1007/s12046-018-1021-9

2. Baradeswaran, S. C.; Vettivel, A.; ElayaPerumal, N.; Selvakumar, R.; Franklin Issac, (2014) Experimental investigation on mechanical behavior, modeling, and optimization of wear parameters of B4C and graphite reinforced aluminum hybrid composites. Materials and Design63, 620-632,

3. Dwivedi, S. P.; Sharma, S.; \& Mishra, R. K.; (2014) Comparison of microstructure and mechanical properties of A356/SiC metal matrix composites produced by two different melting routes. International Journal of Manufacturing Engineering

4. T. B. Rao, (2017) "An experimental investigation on mechanical and wear properties of Al7075/composites: effect of SiC content and particle size," J. Tribol.

5. Manivannan, S. Ranganathan, S. Gopalakannan, S. Suresh, K. Nagakarthigan, and R. Jubendradass, (2017) "Tribological and surface behavior of silicon carbide reinforced aluminum matrix nanocomposite, "Surfaces and Interfaces

6. H. Idrisi and A. I. Mourad, (2017) "Fabrication and wear analysis of aluminum matrix composite reinforced by SiC micro and nanoparticles," in Proceedings of the ASME 2017 Pressure Vessels and Piping Conference, pp. 1-8

7. S. Pradhan, S. Ghosh, T. K. Barman, and P. Sahoo, (2017) "Tribological behavior of Al-SiC metal matrix composite under dry, aqueous and alkaline medium, "Silicon

8. T. Erturk, M. Sahin, and M. Aras, (2016) "Tribological behavior of SiC particulate reinforced AA5754 matrix composite under dry and lubricated conditions," Trans. Indian Inst. Met.,

9. Singla, M (2009) Development of aluminium-based silicon carbide particulate metal matrix composite. Journal of Minerals and Materials Characterization and Engineering, 8(06), 455

10. Rahman, M. H, Al-Rashed, H. M., (2014) Characterization of silicon carbide reinforced aluminium matrix composites. Procedia Engineering. 90, 103-109

11. Prabu, S. B. (2006) Influence of stirring speed and stirring time on the distribution of particles in cast metal matrix composite. Journal of Materials Processing Technology, 171(2), 268-273

12. Sujan, D, (2012) Physio-mechanical properties of Aluminium metal matrix composites reinforced with Al2O3 and SiC. World Academy of Science, Engineering, and Technology, 68 
13. Ozben, T, Kilickap, E., Cakır, O., (2008) Investigation of mechanical and machinability properties of SiC particle reinforced AlMMC. Journal of materials processing technology, 198(1), 220-225

14. Meena, K.; Manna, A. \&Banwait, S.; (2013) An analysis of mechanical properties of the developed Al/SiC-MMC's. American Journal of Mechanical Engineering, 1(1), 14-19

15. Karvanis, K., (2016) Production and mechanical properties of Al-SiC metal matrix composites. in IOP Conference Series: Materials Science and Engineering. IOP Publishing

16. Sarada, N.; Srinivasa Murthy, P. L. Ugrasen, G., (2015) Hardness and wear characteristics of Hybrid Aluminium Metal Matrix Composites Produced by stir casting technique. Materials Today: Proceedings, 2, 2878-2885

17. Kenneth KanayoAlaneme, (2015) Microstructural characteristics, mechanical and wear behavior of aluminum matrix hybrid composites reinforced with alumina, rice husk ash, and graphite. Engineering Science and Technology, an International Journal, $18,416-422$

18. Weiping Chen, Yixiong Liu, Chao Yang, Dezhi Zhu, Yuanyuan Li. (2014) (SiCp+Ti)/7075 Al hybrid composites with high strength and large plasticity fabricated by squeeze casting. Materials Science and Engineering A, 609, 250-254

19. HabiburRahman, Md., Maximum, H. M. Al Rashed. (2014) Characterization of silicon carbide reinforced aluminum matrix composites. Procedia Engineering., 90, 103-109

20. Jia-lei Zhao, Jin-Chuan JIE, Fei Chen, Hang Chen, Ting-juLi, Zhi-Qiang CAO. (2014) Effect of immersion Ni plating on interface microstructure and mechanical properties of Al/Cu bimetal. Trans. Nonferrous Met. Soc. China, 24, 1659-1665

21. Balaguru S, Navin Kumar K\& Elango Natarajan (2018), 'Experimental and Numerical Investigation on Mechanical properties of AA6061T6 Reinforced with SiC and Al2O3' International Journal of Mechanical and Production Engineering Research and Development, 201-206.

22. S. Suresh, G. Harinath Gowd, M. L. S. Deva Kumar (2019). "Mechanical Properties of AA 7075/Al2O3/SiC Nano-metal Matrix Composites by Stir-Casting Method", Journal of The Institution of Engineers (India): Series D. (Springer), DOI: 10.1007/s40033-019-00178-1.

23. Adel A. Omar, M. El-Shennawy \& O. A. Elhabib, "Effect of Cyclic Heat Treatment on Microstructure and Mechanical Properties of C45 Steel”, International Journal of Mechanical Engineering (IJME), Vol. 3, Issue 5, pp. 69-76

24. A. Othman, M. A. Osman, M. H. Wahdan \& A. G. Abed-ElRahim, "Thermal Annealing and UV Induced Effects on the Structural and Optical Prosperities of Capping Free Zns Nanoparticles Synthesized by Co-Precipitation Method", International Journal of General Engineering and Technology (IJGET), Vol. 3, Issue 4, pp. 9-16

25. Nazeema T. H \& Sugannya P. K, "Synthesis and Characterisation of Silver Nanoparticle from Two Medicinal Plants and its Anticancer Property", IMPACT: International Journal of Research in Engineering \& Technology (IMPACT: IJRET), Vol. 2, Issue 1, pp. 49-56

26. Vinay Kumar P\& Mahesh D, "Synthesis and Structural Characterization of Silica Doped Zinc Oxide Nanorods for Photoluminescence Applications", BEST: International Journal of Management, Information Technology and Engineering (BEST: IJMITE), Vol. 3, Issue 11, pp. 33-40 